\title{
Mídias físicas na indústria fonográfica brasileira: uma abordagem gráfica e emocional do design
}

Physical media in the Brazilian phonographic industry: a graphic and

emotional approach to design

\author{
Eluanna Ribeiro das Neves Pereira \\ Universidade Estadual de Londrina \\ eluannar@gmail.com
}

\section{Rogério Zanetti Gomes}

Universidade Estadual de Londrina

rogerioghomes@uel.com $\mathbf{x}$

\section{PROJËTICA}

\section{COMO CITAR ESTE ARTIGO:}

PEREIRA, Eluanna Ribeiro das Neves; GOMES, Rogério Zanetti. Mídias físicas na indústria fonográfica brasileira: uma abordagem gráfica e emocional do design. Projética, Londrina, v. 12, n. 1, p. 220-245, 2021

DOI: 10.5433/2236-2207.2021v12n1p220

Submissão: 01/07/19

Aceite: 11/11/19 
RESUMO: O artigo investiga a indústria fonográfica brasileira quanto às mídias de reprodução musical e sua relação afetiva com o usuário. Apresenta um panorama histórico dos suportes gráficos utilizados e resgata parte da teoria do design emocional para compreender a interação do indivíduo com meios físicos e digitais. O levantamento de dados através de questionário virtual foi realizado juntamente à entrevista com o pesquisador Egeu Laus, a fim de verificar a relação do usuário com os suportes musicais, com enfoque na experiência obtida pela mídia física. Palavras-chave: Indústria fonográfica brasileira. Design gráfico. Design emocional. Mídia física.

ABSTRACT: This paper investigates the Brazilian phonographic industry as to the musical reproduction media and its affective relationship with the user. It introduces a historical overview of the graphic media used and evokes part of the emotional design theory for the comprehension of the interaction between individuals and physical and digital media. The data collection, through a virtual questionnaire, was conducted along with the interview with researcher Egeu Laus, in order to verify the user relationship with musical media, focusing on the experience gained through the physical media.

Keywords: Brazilian phonographic industry. Graphic design. Emotional design. Physical media.

\section{INTRODUÇÃO}

Desde sua origem, a indústria fonográfica é submetida aos avanços tecnológicos existentes no mundo. Muitos deles foram agregadores, permitindo então a maior difusão musical, evolução na qualidade e resolução de problemas relacionados à compactação de conteúdo. Desse modo, a indústria fonográfica também alterou a forma de consumo da matéria em questão, ressignificando seus conceitos e perspectivas. 
Atualmente, as plataformas digitais tomam espaço dos antigos hábitos de consumo musical. Isso acontece devido à velocidade crescente em utilização e demanda de informações, recriando um cenário industrial voltado ao entretenimento e massa. Os indivíduos convergem para a reprodução de músicas online, que, facilitada pela Internet, torna a escuta algo viável e prático.

Por outro lado, a vivência musical difere-se completamente. A experiência voltada à compra do álbum físico, contemplação estética, reprodução e manuseio de conteúdo é relegada a segundo plano. Ainda que exista seu consumo por colecionadores e apreciadores, o número da procura torna-se pequeno, existindo crenças voltadas ao seu término e substituição pelos meios digitais.

As possibilidades existentes no objeto físico, distantes do suporte digital, oferecem maior completude na experiência, trabalhando os sentidos humanos, emoções e memórias afetivas. Dessa forma, há maior contato entre usuário e produto, sendo este capaz de influenciar na construção da personalidade individual.

As teorias do design gráfico e design emocional aparecem, então, como ferramentas de contribuição para as mídias de reprodução musical, assumindo diferentes funções nos contextos e suportes estabelecidos. Suas práticas adaptam-se às tecnologias e demandas, exigindo novas táticas e conhecimentos para atrair o público na valorização dos produtos.

O estudo do design pode auxiliar no entendimento da diferença emocional existente na interação individual com as mídias físicas e digitais. Com isso, o objeto físico musical torna-se artefato presente no tempo e memorizado em cotidianos e vivências, requisitando a compreensão de seus significados por todas as facetas e lados. 


\section{SUPORTE MUSICAL NA INDÚSTRIA FONOGRÁFICA BRASILEIRA}

A indústria fonográfica envolve o processo de produção e distribuição musical. Abrangendo a rede e o mercado da música gravada, possui como produtos o vinil, o CD e o formato digital de música, suportes para reprodução musical.

Desde sua origem, o processo de disseminação de músicas envolveu a transição entre diversos suportes. O fonógrafo, inventado por Thomas Edison no final do séc. XIX, foi o primeiro equipamento a dar início ao mundo da música. Em 1888, há a substituição deste pelo gramofone - inventado por Graham Bell e aperfeiçoado por Emil Berliner. Enquanto o primeiro utilizava-se de cilindros giratórios acionados manualmente, o segundo permitiu a introdução de chapas gravadas como suporte; seus invólucros eram diferentes, tendo distinção no trabalho gráfico. No gramofone, também se destaca a alta possibilidade de tiragens do mesmo conteúdo, desenvolvendo o mercado da indústria fonográfica mundial.

No Brasil, a indústria fonográfica começa seu desenvolvimento a partir da Casa Edison'1, idealizada por Frederico Figner. Nela, Figner traz as novidades musicais do exterior, oferecendo artigos e serviços de gravação musical para o público brasileiro.

No início de sua fundação, a Casa Edison trabalhou com cilindros e equipamentos voltados à utilização do fonógrafo. Os cilindros fonográficos (figura 1) tinham a embalagem feita de papelão e visavam a divulgação do nome da empresa fabricante. Utilizando lettering e grafismos decorativos, não possuía maior função que a de preservação do produto para posterior escuta.

[1] A Casa Edison, nome escolhido para homenagear o criador do fonógrafo, foi a primeira gravadora e distribuidora de discos instaurada no Brasil, permanecendo em atividade de 1902 até 1932. 
Figura 1 - Embalagem de cilindro fonográfico com a marca Edison

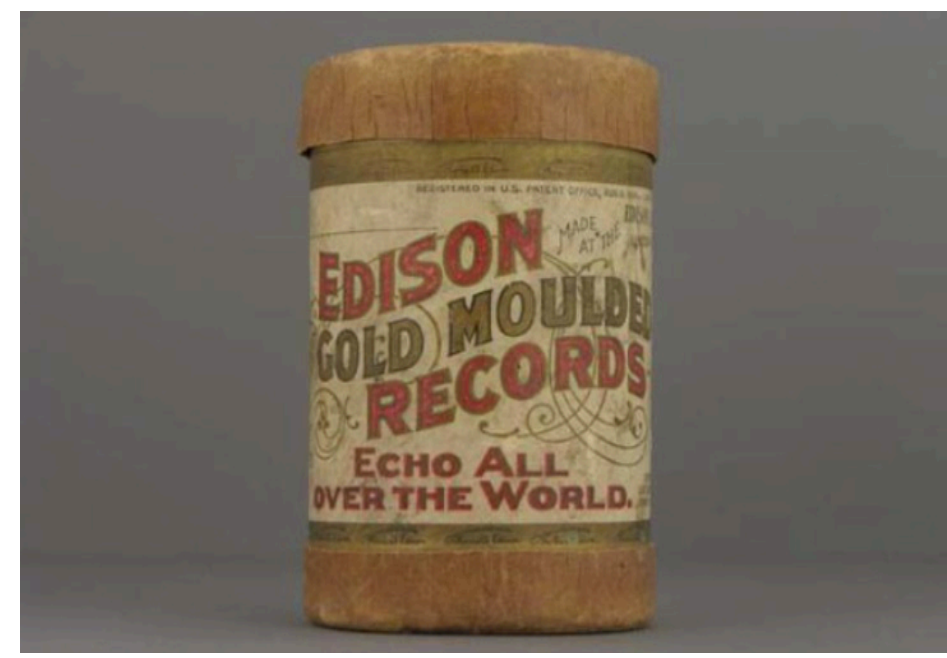

Fonte: autor

Em 1902 o gramofone passa a fazer parte do cenário brasileiro, trazendo o disco como produto direto. Os discos chegavam aos receptores em caixas de papelão com papéis intercalados, não tendo invólucros individuais; suas embalagens eram produzidas pela própria Casa Edison. Egeu Laus (2005) identifica a utilização de um material semelhante ao kraft, papel pardo que portava a marca do fabricante. O formato quadrado, gramatura fina de papel e abertura em um dos lados para a entrada do disco era tido como padrão nos invólucros desenvolvidos.

Surgida em 1913, a fábrica de discos Odeon torna-se a primeira fábrica a prensar e produzir discos na América Latina. Para além da divulgação da marca gravadora, as embalagens dos discos (figura 2) identificavam outros produtos oferecidos pelas empresas, destacando valores e virtudes. A função assumida pela embalagem torna-se a proteção do disco e divulgação de outros produtos disponibilizados. 
Figura 2 - Embalagem de disco da Fábrica Odeon, em papel pardo

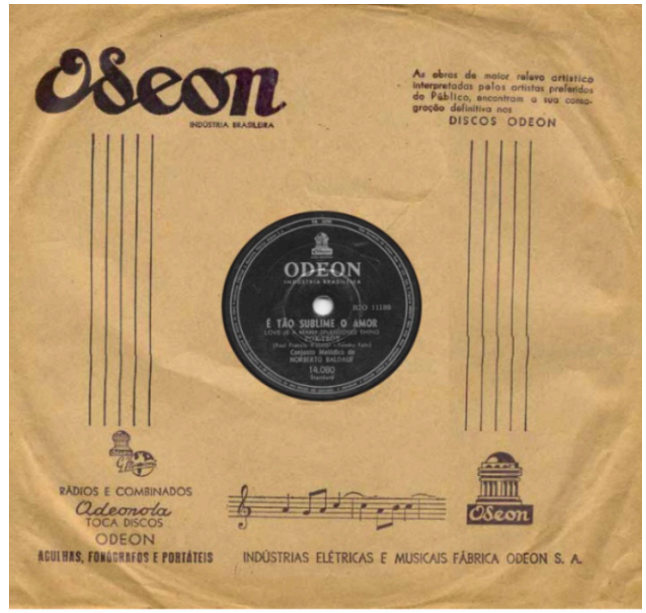

Fonte: autor

Egeu Laus (2005, p. 305) afirma que

"[...] de início os discos eram vendidos quase que exclusivamente pelas casas gravadoras. Posteriormente, outras lojas passaram a revendê-los e a imprimir seus próprios envelopes, [...] aproveitando para anunciar seus próprios produtos que não discos".

Empresas internacionais como RCA-Victor, Columbia Phonograph Corporation, Parlophon (outro selo da empresa Odeon), Brunswick, Columbia e Victor se fixaram no Brasil no ano de 1929, consolidando investimentos e trazendo novas tecnologias para o país. A partir disso, a expansão no mercado musical possibilita a entrada de novas indústrias, artistas e gêneros musicais. A demanda por produtos nacionais se consolida e o rádio comercial auxilia na divulgação da música proveniente da cultura brasileira. 
Em 1940, o design de capas de disco começa a se desenhar enquanto arte gráfica e ferramenta projetual. A partir do surgimento dos álbuns², o design inicia sua influência, criando um conteúdo personalizado para cada peça.

No Brasil, permeia até o ano de 1964 o padrão de embalagens de discos: material kraft sem branqueamento com impressão em uma ou duas cores. No final de 1940 acontece a incorporação de fotografias no projeto, para além da utilização de textos e ilustrações. A fotografia aparece enquanto recurso para relacionar e divulgar repertórios de artistas de sucesso, não sendo "uma capa realmente personalizada" (LAUS, 2005, p. 308), visto que o envelope de um artista podia ser vendido com a relação do repertório de outro.

\subsection{Advento do LP}

No ano de 1948 é lançado em Nova York o primeiro disco de vinil (LP) pela empresa Columbia Records. Sua invenção é atribuída a Peter Goldmark, engenheiro que trabalhou no processo de pesquisa para entrega da novidade. 0 material escolhido para sua composição é derivado do petróleo, substituindo os discos anteriores feitos de goma-laca.

O formato do LP revolucionou o mercado graças a alta durabilidade, prática na manuseabilidade do produto e aumento do tempo disponível para gravação. Tal novidade chega ao Brasil em 1951, dominando o mercado até o ano de 1996. "Carnaval em Long Playing" (figura 3) é o primeiro LP prensado e distribuído no

[2] Os álbuns eram compartimentos personalizados que serviam para juntar diversos discos de uma mesma coletânea. Semelhantes aos álbuns fotográficos, Laus (2005, p. 305) evidencia que tais "álbuns eram comercializados vazios, não tendo inicialmente nenhuma relação direta com a produção fonográfica a ser encartada neles." 
país, trazendo uma coletânea de marchinhas e sambas. O disco foi lançado pela Sinter (Sociedade Interamericana de Representações) - com o selo Capitol - e teve ilustração do capista Paulo Brèves.

Figura 3 - Carnaval em Long-Playing, primeiro vinil lançado comercialmente no Brasil em papel pardo

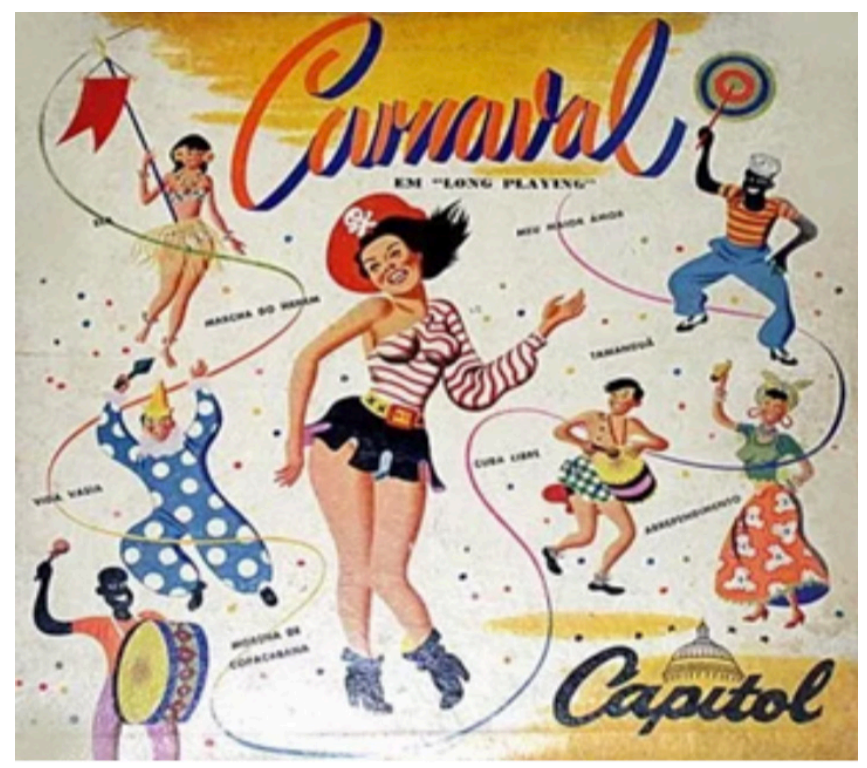

Fonte: Universo do Vinil (2016).

No país, o sucesso do LP deu-se de forma gradual, consolidando-se integralmente apenas na década de 60. Enquanto isso, apenas as capas dos discos eram trabalhadas graficamente, não havendo a incorporação das contracapas no projeto. “O próprio Carnaval em long playing, por exemplo, trazia uma relação de 22 lançamentos em 78 rpm para o carnaval de 1951 e nenhuma informação sobre o conteúdo do próprio disco." (LAUS, 2005, p. 316) 
As contracapas não eram aproveitadas para disposição de informações, sendo seu projeto considerado algo separado do trabalho do capista ${ }^{3}$. Dessa forma, os encartes e livretos só seriam produzidos como parte do disco na década de 70.

Após a consolidação dos LP's enquanto produtos de mercado, há maior demanda para criação em seus suportes; a necessidade de um projeto de embalagem que chame a atenção é tida enquanto elemento primordial para oferecer caráter identitário e despertar o interesse do público para as peças.

Com o surgimento da estética do álbum, os discos passam a serem vistos como obras de arte em si. Com os trabalhos de design dos discos, [...] o LP passa a ser consumido como livros, ou seja, um suporte fechado passível de coleção em discotecas privadas - com status de objeto cultural [...] (DE MARCHI, 2005, p. 13)

Possibilitando maior tempo de gravação e, consequentemente, a estipulação de mais faixas musicais em um só disco, o LP propicia o cuidado gráfico em suas embalagens para identificação do repertório existente; as contracapas são trabalhadas de forma a transmitir todo o conteúdo e mensagem do disco. Além disso, com o auxílio da mídia televisiva na divulgação de novos artistas - função anteriormente desenvolvida pelo rádio -, a imagem do artista, influenciando visualmente o público, é aspecto que suscita o trabalho fotográfico nos suportes. (figura 4).

[...] o LP possibilitou a observação do trabalho do artista, ou seja, um conjunto de canções organizadas em sequência nos dois lados do discos acondicionado em uma capa com determinadas imagens e um encarte com letras transcritas, ficha técnica (músicos e técnicos de gravação) e quaisquer outras informações complementares ao que estava ali gravado. (VARGAS, 2010, p. 92)

[3] No Brasil, o termo capista foi cunhado nos anos 50 para designar o profissional que projetava capas de livros ou discos. Atualmente "recupera [...] alguma visibilidade graças ao aparecimento de novos projectos na área editorial" (CARVALHO, 2008, p. 16), sendo relacionado ao responsável por cuidar visualmente dos projetos de capa. 
Figura 4 - Capa e contracapa do disco "Canção do Amor Demais" (1958), de Elizete Cardoso, lançado pelo Selo Festa; contracapa escrita por Vinícius de Moraes
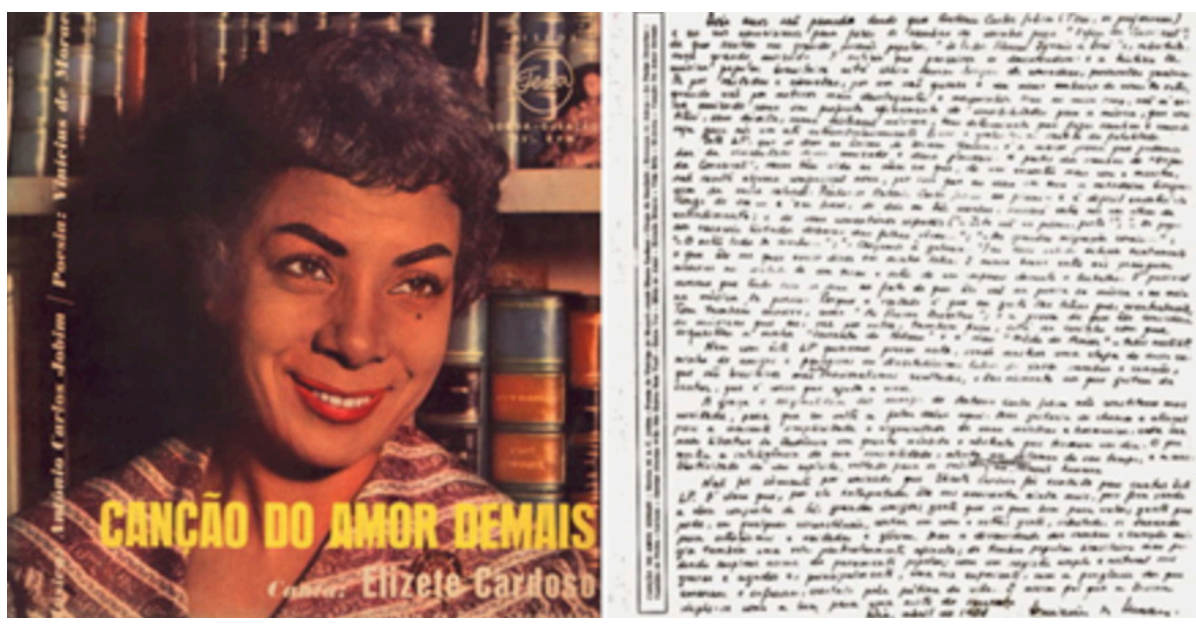

Fonte: Vianna (2018).

O artista se torna elemento essencial no desenvolvimento projetual do disco, tendo seu trabalho representado além da esfera abstrata; a possibilidade de personalização oferece originalidade e singularidade às obras. O álbum é pensado de forma completa, "valorizando ainda mais a parte gráfica e suas relações com a expressão musical." (JANOTTI JUNIOR, 2006, p. 3)

\subsection{O Disco no Contexto Histórico}

Movimento cultural e artístico surgido no final da década de 50, a Bossa Nova foi responsável por influenciar a música e o âmbito visual, oferecendo novas concepções que aliaram imagem e conceito. A gravadora Elenco, criada em 1963, lança diversos discos da música popular brasileira e torna-se criadora das capas emblemáticas da Bossa Nova (figura 5), atribuindo maior parte de sua autoria ao designer Cesar Villela. 
Figura 5 - Capas da Gravadora Elenco; autoria de Cesar Villela
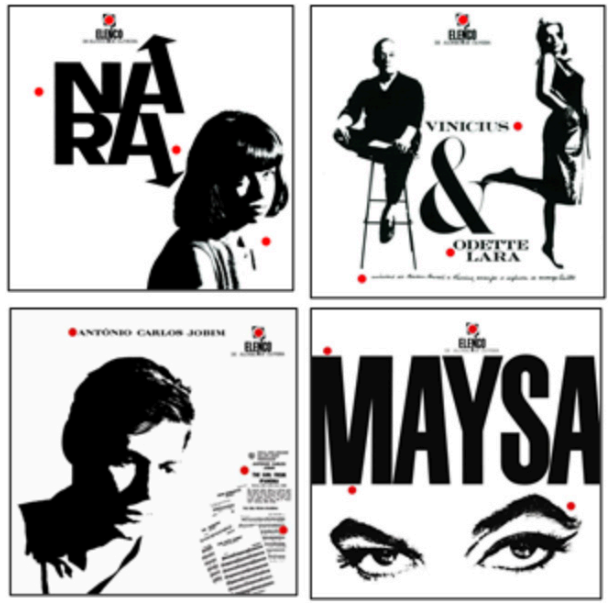

Fonte: Freak Show Business (2018)

Os aspectos relacionados à linguagem musical do gênero foram representados na forma de seu conteúdo físico. Dessa forma, a estética quase minimalista, opondo-se à exageros no conteúdo musical, torna-se objeto de influência para além da música, refletida também nas concepções dos projetos gráficos. As capas de discos elaboradas seriam mais simplificadas e "limpas", sintonizando, segundo Cornutti (2010, p. 6), com a economia verbal e contenção formal dos elementos do gênero. Cria-se um padrão de cores, formas e elementos visuais utilizados na maioria das capas da gravadora Elenco.

A partir de 1967, surge outro movimento musical responsável por influenciar a cultura brasileira: o movimento tropicalista. Atuando na música, teatro, cinema, artes plásticas, moda e design, o tropicalismo se estabelece na divulgação de novos artistas que propagam seus valores em contramão a opressão do regime militar. Com o objetivo de vivenciar uma nova linguagem, permeia entre a inovação estética e a valorização da cultura popular, com um pluralismo sempre presente tendo influência nos projetos de capa. 
A transgressão e quebra dos paradigmas refletiu-se nas capas de discos que viriam com o movimento; as convenções atribuídas graficamente até então foram rompidas, oferecendo lugar para os projetos experimentais. O designer Rogério Duarte é um dos maiores contribuintes da produção gráfica dos discos do período.

Figura 6 - Capa do disco "Caetano Veloso" (1968); projeto de Rogério Duarte

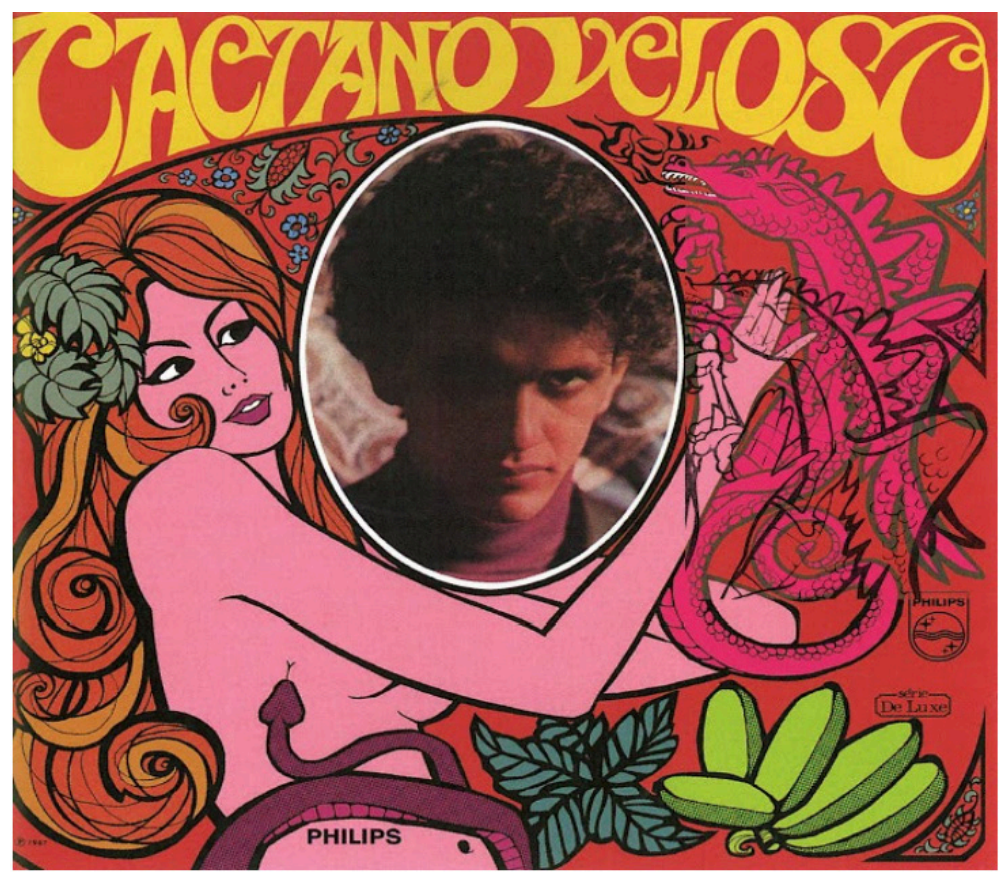

Fonte: Caetano Veloso (1968).

Com o tropicalismo, procurou se desvincular do design funcionalista - presente no visual da Bossa Nova - e das regras do movimento modernista, "trazendo para os projetos das capas de disco uma mudança considerável no modo de criação". (OLIVEIRA; QUELUZ, 2013, p. 663) 
Arts \& Crafts, Art Nouveau, Futurismo, Dadaísmo e Surrealismo, (OLIVEIRA; QUELUZ, 2013, p. 663) fazem parte das influências e mistura de repertórios das capas de discos da Tropicália. A apropriação de elementos também marca presença, juntamente com o choque entre as linguagens. Influenciando diversos capistas, os discos tornam-se reflexo de uma época, retratando as circunstâncias políticas e culturais vigentes.

\section{DESIGN EMOCIONAL}

O Design Emocional surge no final da década de 1990 e tem como característica a valorização do usuário e de sua experiência com objetos e produtos do design; a influência das emoções, percepções e memórias são fundamentais para a teoria.

Anteriormente, os produtos eram valorizados de acordo com sua utilidade, não havendo maiores conceitos agregados. O designer surge enquanto "profissional capacitado a projetar produtos e agregar valores aos mesmos [...]" (FREITAS; CARVALHO; MENESCAL, 2010, p. 2), materializando soluções. Os produtos constituídos apresentam-se como representações carregadas de significados que emergem na interação usuário-objeto, oferecendo espaço ao design voltado ao ser humano, "[...] o seu modo de ver, interpretar e conviver com o entorno." (MONT'ALVÃO; DAMAZIO, 2008, p. 7).

Para além dos produtos funcionalistas pertencentes à era Industrial, é necessário identificá-los enquanto "práticas sociais, preferências e símbolos" (CHAVES; BITTENCOURT; TARALLI, 2013, p. 215), sendo irrevogável a atuação do ser humano na utilização e interpretação do objeto a ser projetado; a participação do usuário é primordial para que se estabeleça um produto voltado para suas necessidades e valorização de suas emoções. 
Mídias físicas na indústria fonográfica... design

PEREIRA, E. R. N.; GOMES, R. Z.

"A maneira como nos relacionamos com os objetos reflete o interior individual; são partes que se somam na construção de sentido da existência."

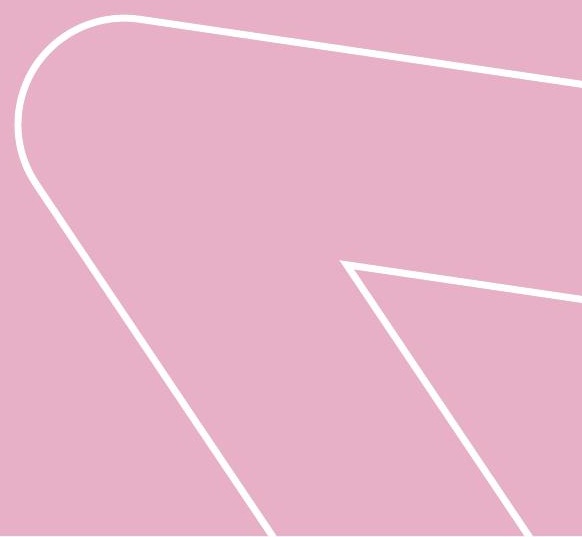


Dessa forma, o estudo dos afetos, sentimentos e sensações de tal usuário na compra e utilização do produto faz-se primordial para entender e projetar produtos que despertem seu interesse; ainda que subjetivas, tais emoções são influenciadas por processos semânticos e culturais, indo além da reação corporal de um organismo. (ENGELEN, 2014, p. 131)

Cria-se uma relação de afeto com determinados artefatos "através do depósito de cargas afetivas aos objetos, e também, mediante os sentimentos gerados em suas experiências de utilização." (NASCIMENTO, 2009, p. 59)

A maneira como nos relacionamos com os objetos reflete o interior individual; são partes que se somam na construção de sentido da existência. Conforme Margolin (2014, p. 64), “[...] o envolvimento com produtos é um componente central do desenvolvimento humano." Com eles, sentimentos de identificação são criados e transferidos; o artefato possui capacidade de definir aspectos sobre a personalidade de quem o possui. Além disso, estão atrelados à cultura material, sendo reflexo de épocas, contextos e sociedades.

As funções de um produto refletem em seus significados, tendo como foco conceitos de emoção, afeto, sentimento e amor. O objeto passa a ser um portador de representações, estabelecendo com o usuário relações em nível subjetivo, emocional e cognitivo. (NIEMEYER, 2008, p. 56)

“O ser humano almeja três coisas: emoção, prazer e significado, objetivam se sentir vivos, sentir o mundo, exigindo diante de tudo um sentido. $O$ ato de valorizar alguma coisa significa que aquele conteúdo ou emoção exerce determinada força sobre o ser humano". (NASCIMENTO, 2009, p. 55) 
Como elemento parte da interação individual com o produto, a experiência influencia o caráter de atribuição de valores e qualidades à objetos que se tem contato. De acordo com Margolin (2014, p. 59) “para que uma situação resulte em experiência, deve ter uma conclusão, bem como uma unidade que lhe confira um sentido de particularidade", incorporando o desejo ou situação vivenciada pelo usuário a singularidade de um objeto.

\subsection{Três Níveis do Design Emocional}

Criado por Donald Norman, um dos pioneiros na pesquisa da ciência cognitiva, os três níveis de estruturas existentes no cérebro humano abrangem as dimensões visceral, comportamental e reflexiva. Norman (2008, p. 26) afirma que "[...] esses três componentes combinam ao mesmo tempo emoções e cognição", possuindo atuação conjunta e identificando a relação dos usuários com os produtos.

O nível visceral é demonstrado como o mais primitivo, ligando-se às aparências encontradas em determinados objetos. É o primeiro encontro do indivíduo com o produto, destinado aos sentimentos causados por ele. De acordo com Norman (2008, p. 56), “o nível visceral é preconsciente, anterior ao pensamento. É onde a aparência importa e se formam as primeiras impressões. O design visceral diz respeito ao impacto inicial de um produto, à sua aparência, toque e sensação."

Nessa dimensão, as decisões de consumo são tomadas de forma rápida e, por vezes, sem muitas reflexões. A estética e identificação são tidas enquanto características importantes, juntamente com as primeiras sensações que o produto pode proporcionar na mente de seu usuário.

O nível comportamental está intimamente ligado com a experiência de uso do produto. A facilidade e prazer efetivo ao utilizar o objeto extrapola a atração 
estética do nível visceral. No entanto, esse nível também não faz racionalizações, sendo envolto por breves cargas afetivas, "[...] sem interpretação ou consciência." (NORMAN, 2008, p. 58)

Relacionando aspectos de desempenho e usabilidade, o nível comportamental procura satisfazer as necessidades ligadas a funcionalidade e a forma como se comporta um objeto na interação com seu usuário. Norman (2008) também afirma que, na experiência com o produto, deve-se levar em conta sua tangibilidade (sensação de peso, textura e superfície), sendo essa responsável por oferecer ao usuário o sentido de controle. Quando manuseamos um produto, estamos tratando do prazer em sentir objetos reais, sendo maior o prazer emocional quando há o contato direto com a substância física do artefato.

A sensação física é importante. Afinal, somos criaturas biológicas, com corpos físicos, braços e pernas. Uma parte enorme do cérebro é ocupada pelos sistemas sensoriais, continuamente investigando e interagindo com o ambiente. [...] Toque, vibração, sensação, cheiro, som, aparência visual. [...] (NORMAN, 2008, p. 102)

Diferente dos anteriores, o nível reflexivo está relacionado com a reflexão e interpretação, criando sentidos com base no aspecto racional. Possuindo caráter de aprofundamento, essa dimensão explora e tenta compreender melhor seu entorno, gerando significados. Sua manifestação é existente em longo prazo, envolvendo sentimentos que não se limitam ao primeiro olhar.

Voltado à subjetividade, o nível reflexivo faz relação com particularidades culturais e é influenciado por elas. Abrange aspectos intangíveis e memória afetiva para trazer significados próprios aos produtos. Dessa forma, os objetos que ligamse ao nível reflexivo podem evocar lembranças em seus usuários, sendo tratados enquanto artefato de memória. Tais produtos são símbolos fonte de associações 
ricas em significados em que "o que realmente importa é a história da interação (...)". (NORMAN, 2008, p. 66)

"Nós nos tornamos apegados a coisas se elas têm uma associação pessoal significativa, se trazem à mente momentos agradáveis e confortantes. [...] Nosso apego não é realmente com a coisa, é com o relacionamento, com os significados e sentimentos que a coisa representa". (NORMAN, 2008, p. 68)

Com isso, as experiências pessoais são parte importante do processo de vínculo com determinados objetos. Tal nível permite que os produtos reforcem "a maneira como vemos a nós mesmos". (NORMAN, 2008, p. 74) Isso está ligado a construção de identidade e autoimagem, sendo os objetos representações e expressões de parte do indivíduo. Dessa forma, há o aumento do sentido de valor do artefato; sentimentos associados a satisfação na exibição, uso e demonstração de um produto se encontram no nível reflexivo, representando particularidades individuais.

\section{METODOLOGIA}

Para aprimorar a pesquisa a respeito dos suportes musicais e experiências do usuário no contato com mídias físicas, criou-se o questionário "Objeto físico musical (CDs e LPs)", baseando-se na relevância cultural e emocional do produto em sua aquisição e manuseio. Disponibilizado através da plataforma Google Forms, no período de 26 a 31 de agosto de 2018, o questionário anônimo obteve um total de 60 respostas. Composto de 8 questões fechadas e 3 abertas, teve público-alvo abrangente: designers e graduandos na área, profissionais relacionados a memória gráfica e, em menor quantidade, pessoas vinculadas a rede de contatos da autora. 
Além disso, uma entrevista realizada com Egeu Laus, autor parte do referencial teórico e pesquisador da memória gráfica brasileira, objetivou a obtenção de respostas do especialista da área. Intitulado como "Design Gráfico, Design Emocional e a Indústria Fonográfica Brasileira", o modelo foi disponibilizado via e-mail, no período de 24 a 30 de outubro de 2018. É constituído por 8 perguntas abertas que visam compreender acerca do trabalho profissional do especialista e entender sobre sua relação com o disco físico, memória emocional e existência dos suportes de reprodução musical sob diferentes contextos.

\section{RESULTADOS}

O questionário "Objeto físico musical (CDs e LPS)" obteve maior percentual de respostas de indivíduos com idade entre 20 e 30 anos (51,7\%), jovens que vivenciaram a transição da mídia física para o meio digital de reprodução musical. Ainda assim, também contou com respostas de diferentes idades, em menor número: $10-20$ anos (25\%), 40-50 anos (13,3\%), 30-40 anos (6,7\%) e 50-60 anos (3,3\%). A maioria dos entrevistados possuem acesso a CDs e LPs, considerando importante seu conteúdo gráfico. A visualidade, como primeiro contato do usuário com o produto pode ser relacionada ao nível visceral, dado por Norman (2008) em sua teoria dos três níveis do Design Emocional. Pode-se entender o conteúdo gráfico enquanto elemento voltado à toda construção projetual do invólucro existente nas mídias físicas, tais como: capa, contracapa, encarte e livreto.

Quando questionados a respeito da experiência vivenciada ao se ter contato com mídias físicas e digitais, 95\% dos indivíduos acreditam tratar-se de interações diferentes. O CD ou LP é considerado um objeto que extrapola sua função primária de reprodução musical, agregando valores estéticos, simbólicos e culturais e despertando outros interesses em seus usuários. 
Figura 7 - Resultado da pergunta 7

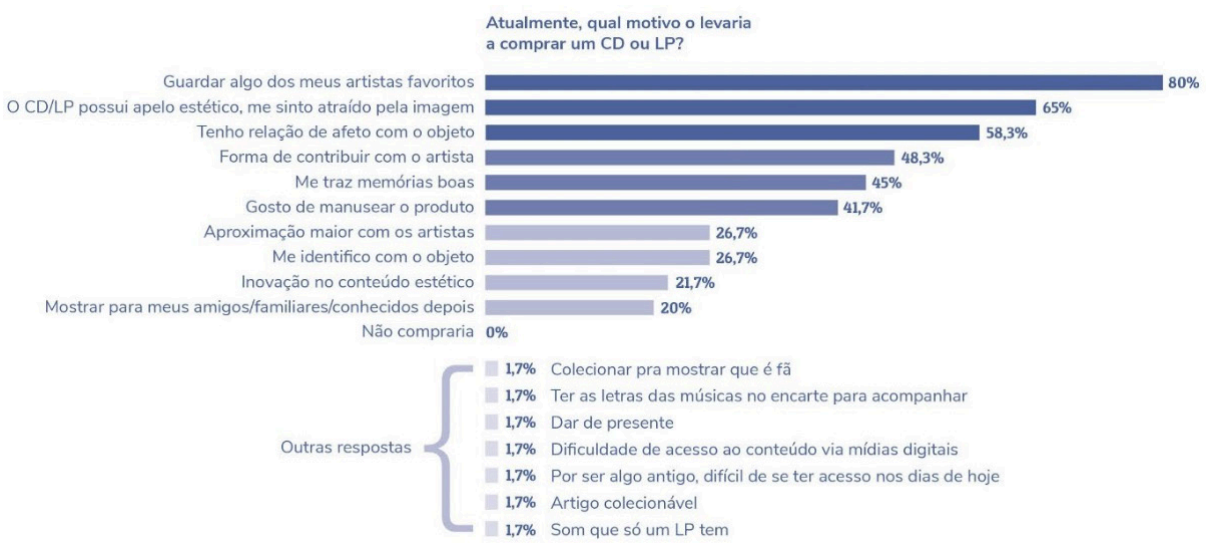

Fonte: Elaborada pela autora.

Atualmente, os motivos que levariam a compra de um CD ou LP variam de acordo com o gráfico (figura 7). 80\% dos indivíduos responderam que comprariam um objeto físico de reprodução musical para "guardar algo dos seus artistas favoritos", demonstrando a relação emocional diretamente vinculada ao artista e seu trabalho. A "forma de contribuir com o artista" (48,3\%) ou a "aproximação maior" (26,7\%) com ele também são motivos que auxiliam no aspecto de valorização do trabalho, desenvolvendo o laço emocional entre fã e músico.

O apelo estético e atração do objeto gerou $65 \%$ das respostas. Isso pode ser explicado por ser o disco a primeira interface de contato emocional do indivíduo com o conteúdo proposto. Nesse caso, o nível visceral comanda muitas decisões pela estima visual.

A construção do desejo é obtida também através da identificação que o produto proporciona no usuário, importante na definição da personalidade e construção da aparência individual. Tal sentimento é exposto de forma clara 
na resposta relacionada a "identificação com o objeto" (26,7\%). Dessa forma, o indivíduo consegue se reconhecer no artefato, criando vínculos e retratando parte de sua própria imagem. A identidade está muito relacionada ao aspecto de "relação de afeto com o objeto" (58,3\%), construída por vários fatores. Características como visualidade, identificação, memória ou significados atribuídos podem ser relacionados ao sentimento criado no indivíduo sobre o produto.

O nível comportamental, exemplificado por Norman (2008), traz consigo a importância da tangibilidade na interação do sujeito com o produto. Dessa forma, a resposta referente ao "manuseio do produto" $(41,7 \%)$ é relativa a importância material de um objeto que compartilha de sua textura e forma para dar sentido à experiência individual. Ao manusear um produto temos controle sobre ele e estamos submetidos às mais diversas sensações; o prazer torna-se maior quando em contato com substâncias físicas e objetos reais.

O manuseio do produto e sua palpabilidade são elementos agregadores para a experiência tátil. Quando comparado a experiência digital, a mídia física é tida enquanto "importante por proporcionar maior proximidade entre a música/ banda e ouvinte. [...]" visto que "ter um CD é como ter um livro, é palpável e tem cheiro, ao contrário de uma mídia digital, uma música baixada da internet ou um ebook. [...]".

A entrevista com Egeu Laus questiona a diferença emocional existente entre os suportes de reprodução musical. Egeu afirma que ouvir uma música é também uma experiência tátil, sendo fundamental o manuseio do disco quando se escuta o conteúdo. Dessa forma, também considera a materialidade do álbum físico um elemento importante, agregando na vivência musical. Segundo Laus, o renascimento do LP no contexto atual é símbolo que reflete a importância da busca pela materialidade. 
Sobre memórias afetivas, Laus acredita que o aspecto visual do disco é responsável por direcionar nossas emoções a determinados momentos significativos, revisitando sensações e experiências já vivenciadas. Nesse caso, o nível visceral apresentado por Norman (2008) é quem origina os primeiros impactos emocionais. Voltado a aparência dos objetos, tal nível direciona nossos pensamentos e emoções, oferecendo percepções rápidas acerca de seu conjunto. Enquanto a atração é tida por tal dimensão, é apenas no nível reflexivo que as sensações proporcionadas pelas lembranças tomam forma e são absorvidas, interpretadas e guardadas de forma afetiva e a longo prazo.

Assumindo diferentes posições culturais, o disco muda seu papel e objetivo devido aos contextos sociais estabelecidos. Para Egeu, anteriormente, ouvir um disco era quase um ritual - envolvendo a escolha do produto, sua escuta e manuseio -, uma experiência coletiva que se perdeu devido às circunstâncias atuais.

\section{CONSIDERAÇÕES FINAIS}

A mídia de reprodução musical se mostra presente e aliada ao universo da música desde sua origem. Contemplando diversos suportes, faz-se necessária uma peça física ou digital para atender demandas e transmitir o conteúdo de tal sistema. No Brasil, a indústria fonográfica cria corpo em diferentes invólucros que se transformaram através do tempo: fonógrafo e cilindros fonográficos, gramofone e disco, CD e plataformas do meio digital são alguns exemplos da evolução dos suportes.

Parte do desenvolvimento social e ascensão da tecnologia, tal mudança reflete na mídia digital como atual e predominante, sendo inegável sua praticidade, qualidade e capacidade de armazenamento. Portanto, o trabalho apresentado não pretende invalidar os valores agregados com tais plataformas; a monografia busca expandir os conceitos acerca dos suportes musicais e sua importância na vivência emocional dos indivíduos. 
O resgate contextual e histórico sobre a indústria fonográfica brasileira, analisando a diferença e desenvolvimento dos projetos gráficos foi aliado à teoria do design emocional, a fim de entender particularidades a respeito dos significados presentes nos suportes quando submetidos a interação com seus usuários. O objeto físico foi, então, especificado enquanto foco da pesquisa, devido ao comum apreço por tais artefatos e constatação do momento transitório que a mídia presente no mercado musical percorre atualmente.

Os níveis do design emocional oferecem parâmetro sobre o impacto afetivo na escolha e posse de um artefato, destacando a importância de elementos visuais, tangíveis e simbólicos que contribuem para o disco com características que ultrapassam sua função primária.

Ferramenta de validação da teoria retratada, a aplicação do questionário possibilitou a descoberta das subjetividades presentes nas emoções de seus consumidores quanto ao contato com o disco físico. Pensamentos nostálgicos, afeição por artistas favoritos, lembranças pessoais e atribuições de significados ao objeto são parte das respostas que comprovam o vínculo de um indivíduo com seu artefato musical.

Além disso, a entrevista com o pesquisador Egeu Laus fez-se importante para constatação da teoria demonstrada, oferecendo parâmetros específicos da área em questão. A diferença entre as mídias de reprodução musical, quando aplicadas em contextos passados e atuais, tornam-se reflexo da sociedade; entender sua transição é fundamental para compreender parte dos aspectos culturais, políticos, econômicos e sociais existentes no país. Enquanto objeto presente na cultura material, os discos tornam-se também importante acervo que documenta a construção da história musical.

Como objeto teórico voltado à análise emocional, o trabalho conclui seus objetivos e abordagens, contribuindo e propondo a reverberação do estudo. As mídias de reprodução musical requerem abordagens gráficas e emocionais proporcionando conhecimentos subjetivos que devem ser revisitados, por fazer parte da cultura e das transformações envolvidas na sociedade. 


\section{REFERÊNCIAS}

1. CARVALHO, Ana Isabel Silva. A capa de livro: o objecto, o contexto, o processo. 2008. Dissertação (Mestrado em Design da Imagem) - Faculdade de Belas Artes, Universidade do Porto, Porto, Portugal, 2008.

2. CHAVES, Iana Garófalo; BITTENCOURT, João Paulo; TARALLI, Cibele Haddad. O design centrado no humano na atual pesquisa brasileira: uma análise através das perspectivas de Klaus Krippendorff e da IDEO. Holos, Natal, RN, ano 29, v. 6, p. 213-225, dez. 2013. Disponível em: http://www.redalyc.org/ articulo.oa?id=481548608018. Acesso em: 24 jul. 2018.

3. CORNUTTI, Camila. As capas de disco como registros visuais da Bossa Nova. In: CONGRESSO BRASILEIRO DE CIÊNCIAS DA COMUNICAÇÃO, 33., 2010. Caxias do Sul, RS. Anais [...]. Caxias do Sul: Intercom - Sociedade Brasileira de Estudos Interdisciplinares da Comunicação, 2010. p. 1-15,

4. DE MARCHI, Leonardo. A angústia do formato: uma história dos formatos fonográficos. E-Compós, Rio de Janeiro, RJ, v. 2, abr. 2005. DOI: https://doi. org/10.30962/ec.29.

5. ENGELEN, Eva-Maria. Significado e emoção. In: BAITELLO JUNIOR, Norval; WULF, Christoph (org.). Emoção e imaginação: os sentidos e as imagens em movimento. São Paulo: Estação das Letras e Cores, 2014. p. 129-140.

6. FREAK SHOW BUSINESS. Capas dos discos da gravadora Elenco. Disponível em: https://freakshowbusiness.wordpress.com/. Acesso em: 24 jul. 2018.

7. FREITAS, Ranielder Fábio de; CARVALHO, Cintya Oliveira de; MENESCAL, Richarley Envangelista. Design emocional e o designer como interpretador 
Projética, Londrina, v. 12, n. 1, p. 220-245, março 2021

de desejos e necessidades: revisão de literatura. Estudos em Design, Rio de Janeiro, v. 18, n. 1, p. 1-18, 2010.

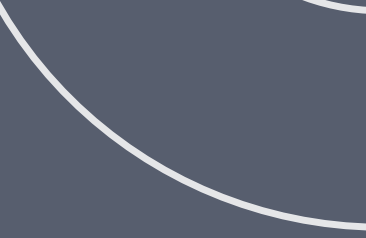

8. JANOTTI JUNIOR, Jeder. Mídia, música popular massiva e gêneros musicais: a produção de sentido no formato canção a partir de suas condições de produção e reconhecimento. In: ENCONTRO ANUAL DA COMPÓS: Associação Nacional de Programas de Pós-graduação em Comunicação, 15., 2006, Bauru, SP. Anais [...]. Bauru: UNESP, 2006. p. 1-12.

9. LAUS, Egeu. Capas de discos: os primeiros anos. In: CARDOSO, Rafael (org.). O design brasileiro antes do design: aspectos da história gráfica, 1870-1960. São Paulo: Cosac Naify, 2005. p. 296-336.

10. MARGOLIN, Victor. A experiência com os produtos. In: MARGOLIN, Victor. Políticas do artificial: ensaios e estudos sobre design. Rio de Janeiro, Civilização Brasileira, 2014. p. 55-80.

11. MONT'ALVÃO, Claudia.; DAMAZIO, Vera (org.). Design, ergonomia e emoção. Rio de Janeiro: Mauad X, 2008.

12. NASCIMENTO, Deise Rosa do. Design emocional: a linguagem dos sentimentos. Brasília: UNICEUB, 2009.

13. NIEMEYER, Lucy. Design atitudinal: uma abordagem projetual. In: MONT'ALVÃO, Claudia; DAMAZIO, Vera (org.). Design, ergonomia e emoção. Rio de Janeiro: Mauad X, 2008. p. 55-56.

14. NORMAN, Donald Arthur. Design emocional: por que adoramos (ou por que adoramos (ou detestamos) os objetos do dia-a-dia. Rio de Janeiro: Editora Rocco, 2008. 
Mídias físicas na indústria fonográfica... design PEREIRA, E. R. N.; GOMES, R. Z.

15. OLIVEIRA, Cauhana Tafarelo de; QUELUZ, Marilda Lopes Pinheiro. Design gráfico tropicalista: as capas de disco no contexto do Brasil da década de 1960. In: ENCONTRO NACIONAL DE ESTUDOS DA IMAGEM, 4., 2013, Londrina, PR. Anais [...]. Londrina: UEL, 2013. p. 652-670.

16. UNIVERSO DO VINIL. 21 de junho de 1948 o dia que nasceu o vinil e os seus 67 anos no Brasil. 2016. Disponível em: https://universodovinil.com. br/2016/04/17/21-de-junho-de-1948/. Acesso em: 24 jul. 2018.

17. VARGAS, Herom. Condições e contexto midiático do experimentalismo na MPB dos anos 1970. Intexto, Porto Alegre, RS, v. 2, n. 23, p. 87-102, jul./dez. 2010.

18. VELOSO, Caetano. (Tropicália): Caetano Veloso: vida e obra em Progresso. Caetano completo, blog. [S. 1], 1968. Disponível em: http://caetanocompleto. blogspot.com/search/label/1967. Acesso em: 24 jul. 2018.

19. VIANNA, Luiz Fernando. Ainda bossa, ainda nova. Rio de Janeiro, RJ: Instituto Moreira Salles, 2018. Disponível em: https://ims.com.br/2018/03/29/aindabossa-ainda-noval. Acesso em: 24 jul. 2018.

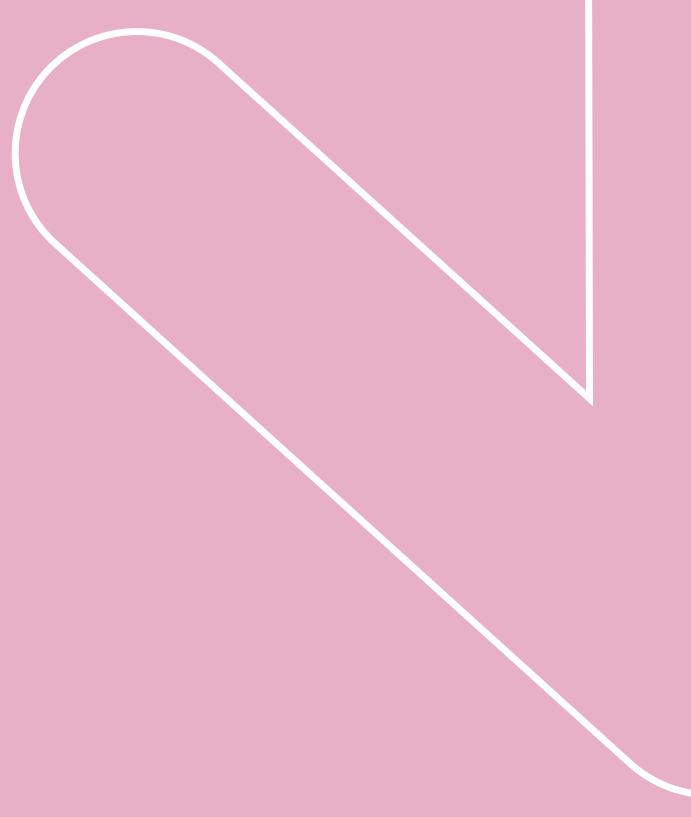

